\title{
$\mathrm{CiSj}$
}

\section{OPTIMIZATION OF PIECEWISE NON-LINEAR MULTI CONSTRAINED ECONOMIC POWER DISPATCH PROBLEM USING AN IMPROVED GENETIC ALGORITHM}

\author{
B. Padmanabhan, R. S. SivaKumar, J. Jasper \\ Ponjesly College of Engineering, Nagercoil, India \\ padmanabhan_balu@yahoo.co.in, shiross912@yahoo.com, mailtojasper@gmail.com
}

\begin{abstract}
In this paper, a more realistic formulation of the Economic Dispatch problem is proposed, which considers practical constraints and non linear characteristics. The proposed ED formulation includes ramp rate limits, valve loading effects, equality and inequality constraints, which usually are found simultaneously in realistic power systems. This paper presents a novel Genetic Algorithm to solve the economic load dispatch (ELD) problem of thermal generators of a power system. This method provides an almost global optimal solution, since they don't get stuck at local optimum. The proposed method and its variants are validated for the two test systems consisting of 3 and 10 thermal units whose incremental fuel cost functions takes into account the valve-point loading effects.
\end{abstract}

Keywords: Economic load Dispatch, Genetic Algorithm, Valve-point loading, Ramp rate limits, Roulette selection

\section{INTRODUCTION}

Economic Load Dispatch (ELD) seeks "the best" generation for the generating plants to supply the required demand plus transmission losses with the minimum production cost. Improvement in scheduling the units output can lead to significant cost savings. In traditional ELD problems, the cost function of each generator is approximately represented by a simple quadratic function and is solved using mathematical programming based on several optimization techniques such as dynamic programming, Linear programming, homogenous linear programming and quadratic programming methods[1],[2]-[4]. However none of these methods may be able to provide an optimal solution and they usually get stuck at a local optimum. Normally the input-output characteristic of modern generating units are highly non-linear in nature due to valve-point effect [19]-[22], ramp-rate limits, Fuel switching [14]-[15] etc, having multiple local minimum points in the cost function. To overcome such difficulties many heuristic search algorithms, such as Genetic algorithm [5], Differential Evolution [6], Tabu search $[7,8]$, etc., have been proposed to solve ELD problem. These techniques can be used to search the global optimum with any type of objective function and constraints. In this paper, two ED problem for 3 and 10 thermal units with a non smooth fuel cost function [9] are employed to demonstrate the performance of the proposed method. This paper employs genetic algorithm to solve the non convex and non smooth cost function.

The rest of this paper is organized as follows: Section II describes the formulation of an ED problem; while section III explains the standards in GA. Section IV then details the procedure of handling the GA. Section V gives the flow chart. Section VI gives the Data's and Section VII gives the results of the optimization. Section VIII outlines our conclusion and future research.

\section{PROBLEM DESCRIPTION}

The objective of ED is to determine the generation levels for all on-line units which minimize the total fuel cost, while satisfying a set of constraints. It can be formulated as follows:

\subsection{ECONOMIC DISPATCH (ED) PROBLEM FORMULATION}

The fuel cost functions of the generating units are usually described by a quadratic function of power output. Thus the objective function is given as:

Minimize:

$$
F_{i}\left(P_{i}\right)=a_{i} P_{i}^{2}+b_{i} P_{i}+c_{i}
$$

where

$a_{i}, b_{i}, c_{i}$ - the fuel cost coefficients of the ith unit

$N$ - Number of generating units in the system

$P_{i}$ - output generation of ith unit.

1. Power balance constraint: 


$$
\sum_{i=1}^{N} P_{i}=P_{D}+P_{L}
$$

where

$P_{D}-$ Total power demand

$P_{L}-$ Total network losses

2. Capacity limits constraints:

$$
P_{i}^{\min } \leq P_{i} \leq P_{i}^{\max }
$$

where

$$
\begin{aligned}
& P_{i}{ }^{\min }-\text { minimum generation limit } \\
& P_{i}{ }^{\text {max }}-\text { maximum generation limit }
\end{aligned}
$$

\subsection{VALVE POINT EFFECT}

Large steam turbine generators will have a number of steam admission valves that are opened in sequence to obtain ever-increasing output of the unit. As the unit loading increases the input to the unit increases and the incremental heat rate decreases between the opening points for any two valves [10], however, when a valve is first opened, the throttling losses increases rapidly and the incremental heat rate rises suddenly. This is "valve point" effect which leads to non-smooth, nonconvex input-output characteristics, to be solved using the heuristic techniques. The valve point effect is incorporated in ED problem by superimposing the sine component model on the quadratic cost curve which is given below,

$$
F_{i}^{*}\left(P_{i}\right)=F_{i}\left(P_{i}\right)+e_{i} \sin \left(f_{i}\left[P_{i}^{\min }-P_{i}\right]\right)
$$

where

$F_{i}^{*}\left(P_{i}\right)$ - fuel cost if ith unit with valve point effect

$e_{i}, f_{i}$ - the fuel cost coefficients of the ith unit with valve point effect.

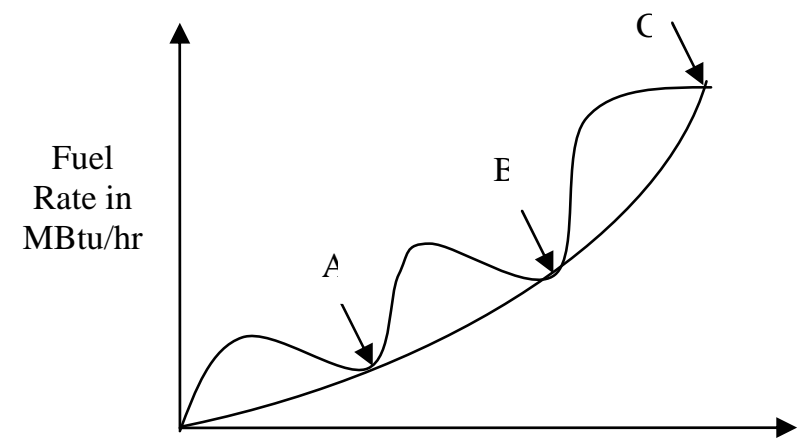

Generations in MW

Fig. 1 - Valve point curve

\subsection{RAMP RATE LIMITS:}

The Ramp-Up and Ramp-Down rate limits of $i^{\text {th }}$ generator are given by

As generation increases

$$
P_{i}-P_{i 0}<=U R_{i}
$$

As generation decreases

$$
P_{i}-P_{i 0}<=D R_{i}
$$

and

$$
\max \left(P_{i}^{\min }, P_{i 0}-D R\right)<=P_{i}<=\min \left(P_{i}^{\max }, P_{i 0}+U R\right)
$$

Where Pi is the current output power and Pi0 is the output power in the previous interval of the $i^{\text {th }}$ generator unit. $\mathrm{UR}_{\mathrm{i}}$ is the up-ramp rate limit of the $\mathrm{i}^{\text {th }}$ generator and $\mathrm{DR}_{\mathrm{i}}$ is the down-ramp rate limit of the $\mathrm{i}^{\text {th }}$ generator.

\section{OPTIMIZATION USING GENETIC ALGORITHM}

\subsection{BASIC FUNDAMENTALS OF GA}

Genetic Algorithm (GA) is a search algorithm based on the conjecture of natural selection and genetics. The features of genetic algorithm are different from other search techniques in several aspects.

- First, the algorithm is a multi-path that searches many peaks in parallel, and hence reducing the possibility of local minimum trapping.

- Secondly, GA works with a coding of parameters instead of the parameters themselves. The coding of parameter will help the genetic operator to evolve the current state into the next state with minimum computations.

- Thirdly, GA evaluates the fitness of each string to guide its search instead of the optimization function.

- Three basic operators of GA are reproduction, crossover, and mutation

\subsection{BASIC OPERATORS OF GA}

Reproduction: A mechanism by which the most highly fit members in a population is selected to pass on information to the next population of members. It effectively selects the fittest of the springs in the current population to be used in generating the next population. In this way, relevant information concerning the fitness of a string is passed along to successive generations.

Crossover: A mechanism by which strings can exchange information, possibly creating more highly fit strings in the process and allowing the exploration of new regions of the search space.

Mutation: It ensures that a string position will never be fixed at a certain value for all time.

\subsection{ALGORITHM FOR GA}

1. Code the problem variables into binary strings.

2. Randomly generate initial population strings. Tossing of a coin can be used. 
3. Evaluate fitness values of population members

4. If solution available among the population? then Stop, else Continue.

5. Select highly fit strings as parents and produce offspring's according to their fitness.

6. Create new string by mating current offspring. Apply crossover and mutation operators to introduce variations and form new strings.

7. New springs replace existing one.

8. GOTO step 4 and repeat

9. Stop.

\section{IMPLEMENTATION OF GA}

\subsection{CODING:}

Implementation of problem in a genetic problem starts from the parameter encoding. It is carefully done to utilize the genetic algorithm's ability to efficiently transfer information between chromosome strings and objective function of the problem. Binary coded strings 1 s and 0 s are used.

\subsection{FITNESS FUNCTION:}

Genetic algorithm mimics the survival of the fittest principle of nature to make a search process. Therefore, the Genetic Algorithm problems are naturally suitable for maximization problems. Minimization problems are usually converted into the maximization problems using some suitable transformations, The fitness function for maximization problem is given by $\mathrm{f}(\mathrm{x})=\mathrm{F}(\mathrm{x})$ and for minimization $\mathrm{f}(\mathrm{x})=[1 / 1+\mathrm{F}(\mathrm{x})]$.

In order to emphasize the best chromosome and speed up the convergence of the evolutionary process, fitness function is normalized into the range between 0 and 1 . The fitness function of the ith chromosome is given by

$$
f_{i}(x)=1 /\left[1+k\left(\left(F_{i}(x) / F\right)-1\right)\right]
$$

where

$F_{i}(x)$ is the solution corresponding to the ith chromosome

$f_{i}{ }^{\min }$ is the solution of the highest ranking chromosome

$\mathrm{k}$ is the scaling constant

\subsection{REPRODUCTION}

The reproduction genetic algorithm operator selects the good strings in a population and forms a matting pool. The commonly used selection operator is the proportionate reproduction operator where a string is selected from the mating pool with a probability proportional to its fitness. The probability of selecting the $\mathrm{i}^{\text {th }}$ string is

$$
p_{i}=f / \sum_{j=1}^{L} f_{i}
$$

where

$\mathrm{L}$ is the population size

$f_{i}$ is the fitness function of the ith population

This selection scheme is implemented by using the roulette-wheel [11] with its circumference marked for each string proportionate to the string's fitness.

\subsection{COMPETITION AND SELECTION}

Each individual in the combined population has to compete with some other individuals to have a chance to be copied to the next generation. The score of each trial vector after stochastic competition is given by

$$
w_{i}=\sum_{n=1}^{L} w_{n}
$$

\subsection{CROSSOVER OPERATOR}

In crossover the information is exchanged among stings of the mating pool to create new strings. In the crossover operator the good substrings from parent strings will be combined to form a better child offspring. There are three forms of crossover:

- One point crossover

- Uniform crossover

- Multi point crossover

The effect of crossover may be detrimental or beneficial. The crossover has three distinct substeps, namely:

- Slice each of parent in the substrings

- Exchange a pair of corresponding substrings of parents

- Merge the two respective substrings to form offspring.

\subsection{MUTATION}

Mutation is the important operator, because newly created individuals have no new inheritance information and the number of alleles is decreasing. This process results in the contraction of the population to one point. Diversity is necessary to search a big part of the search space. It is achieved by the mutation.

Mutation operator changes 1 to 0 and vice versa with a small mutation probability. The bit-wise mutation is performed bit-by-bit by flipping the coin with required probability. In general, mutation probability is fixed throughout the whole search processing. However a small fixed mutation probability can only result in a premature convergence, while the search with a large fixed mutation probability will not converge. 


\section{FLOW CHART}

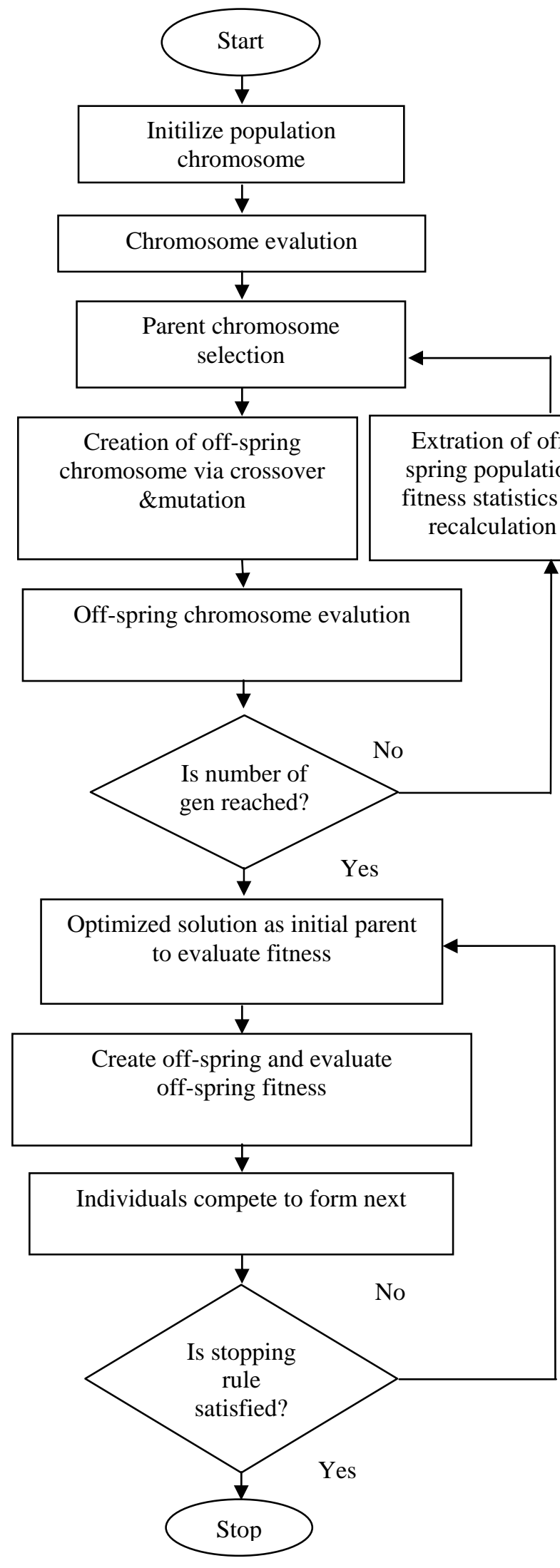

\section{DATA'S AND RESULT}

\subsection{TEST CASE I}

3-generator System: The unit characteristics data are given in Table 1,2 and 3. The load demand is $850 \mathrm{MW}$. The B loss coefficients are given in the Table 4.[12]

Table 1. Capacity and Cost Co-Efficient

\begin{tabular}{|c|c|c|c|}
\hline Quantities & Unit-1 & Unit-2 & Unit-3 \\
\hline ai & 0.004820 & 0.001940 & 0.001562 \\
\hline bi & 7.97 & 7.85 & 7.92 \\
\hline ci & 78 & 310 & 562 \\
\hline Pimin & 50 & 100 & 100 \\
\hline Pimax & 200 & 400 & 600 \\
\hline
\end{tabular}

Table 2. Valve-Point Loading

\begin{tabular}{|c|c|c|c|}
\hline Quantities & Unit-1 & Unit-2 & Unit-3 \\
\hline ei & 150 & 200 & 300 \\
\hline Fi & 0.063 & 0.042 & 0.0315 \\
\hline
\end{tabular}

Table 3. Ramp Rate Limits

\begin{tabular}{|c|c|c|c|}
\hline Unit & Pio & URi & DRi \\
\hline 1 & 170 & 50 & 90 \\
\hline 2 & 350 & 80 & 120 \\
\hline 3 & 440 & 80 & 120 \\
\hline
\end{tabular}

Table 4. B-Coefficients

$$
\begin{aligned}
& \mathrm{B}=\left[\begin{array}{lll}
0.0006760 & 0.0000953 & -0.0000507 \\
0.0000953 & 0.0005210 & 0.0000901 \\
-0.0000507 & 0.0000901 & 0.0002940
\end{array}\right] \mathrm{MW}^{-1} \\
& \mathrm{~B}_{0}=\left[\begin{array}{lll}
-0.07660 & -0.00342 & 0.01890
\end{array}\right] \\
& \mathrm{B}_{00}=[4.0357] \mathrm{MW}
\end{aligned}
$$

\subsection{TEST CASE II}

10-generator Systems: The load demand is 2000MW. The unit characteristics data are given in the Table 5, 6 and 7. The system B loss coefficients are given in the Table 8.

Fig. 2 - Flowchart for Genetic Algorithm. 
Table 5. Capacity AND Cost Co-Efficient

\begin{tabular}{|c|c|c|c|c|c|}
\hline Unit & $\mathrm{a}_{\mathrm{i}}$ & $\mathrm{b}_{\mathrm{i}}$ & $\mathrm{c}_{\mathrm{i}}$ & Pimin & Pimax \\
\hline 1 & 0.1524 & 38.5379 & 786.7988 & 150 & 470 \\
\hline 2 & 0.1058 & 46.1591 & 451.3251 & 135 & 470 \\
\hline 3 & 0.0280 & 40.3965 & 1049.9977 & 73 & 340 \\
\hline 4 & 0.0354 & 38.3055 & 1243.5311 & 60 & 300 \\
\hline 5 & 0.0211 & 36.3278 & 1658.5696 & 73 & 243 \\
\hline 6 & 0.0179 & 38.2704 & 1356.6592 & 57 & 160 \\
\hline 7 & 0.0121 & 36.5104 & 1450.7045 & 20 & 130 \\
\hline 8 & 0.0124 & 36.5104 & 1450.7045 & 47 & 120 \\
\hline 9 & 0.1090 & 39.5804 & 1455.6056 & 20 & 80 \\
\hline 10 & 0.1295 & 40.5407 & 1469.4026 & 10 & 455 \\
\hline
\end{tabular}

Table 6. Valve-Point Loading

\begin{tabular}{|c|c|c|}
\hline Quantities & $\mathrm{e}_{\mathrm{i}}$ & $\mathrm{f}_{\mathrm{i}}$ \\
\hline Unit-1 & 450 & 0.041 \\
\hline Unit-2 & 600 & 0.036 \\
\hline Unit-3 & 320 & 0.028 \\
\hline Unit-4 & 260 & 0.052 \\
\hline Unit-5 & 280 & 0.063 \\
\hline Unit-6 & 310 & 0.048 \\
\hline Unit-7 & 300 & 0.086 \\
\hline Unit-8 & 340 & 0.082 \\
\hline Unit-9 & 270 & 0.098 \\
\hline Unit-10 & 380 & 0.094 \\
\hline
\end{tabular}

Table 7. Ramp Rate Limits

\begin{tabular}{|c|c|c|c|}
\hline Quantities & Pio & URi & DRi \\
\hline Unit-1 & 90 & 80 & 120 \\
\hline Unit-2 & 400 & 80 & 120 \\
\hline Unit-3 & 100 & 70 & 105 \\
\hline Unit-4 & 95 & 65 & 100 \\
\hline Unit-5 & 80 & 60 & 90 \\
\hline Unit-6 & 105 & 60 & 100 \\
\hline Unit-7 & 100 & 130 & 130 \\
\hline Unit-8 & 90 & 100 & 120 \\
\hline Unit-9 & 40 & 80 & 80 \\
\hline Unit-10 & 40 & 80 & 120 \\
\hline
\end{tabular}

Table 8. B-Coefficients

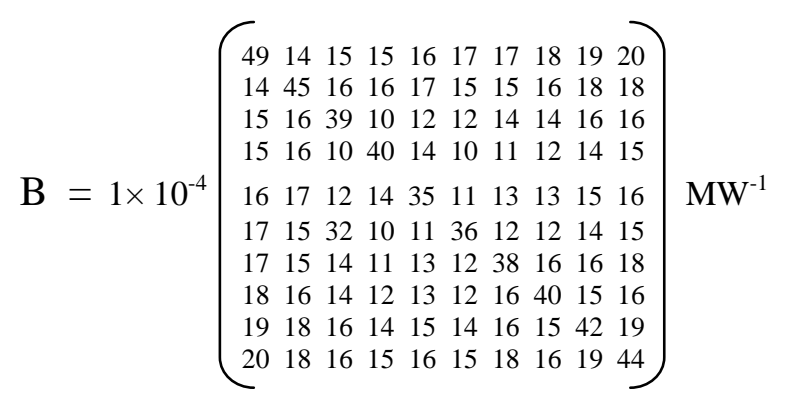

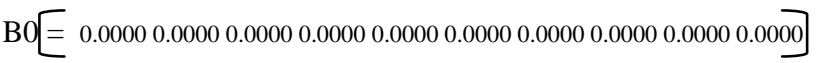

$$
\mathrm{B} 00=[0.00000]
$$

Table 9. Convergence Results for 3 Generating Units With Valve Point Effect \& Losses

$\mathrm{PD}=850 \mathrm{MW}$

No. of Trials $=50$

No. of Population $=5$

Crossoverrate $=0.8$; MutRate $=0.001$

\begin{tabular}{|c|c|c|c|}
\hline Quantities & Res-1 & Res-2 & Res-3 \\
\hline P1(MW) & 148.67 & 146.75 & 146.56 \\
\hline P2(MW) & 297.33 & 293.5 & 293.12 \\
\hline P3(MW) & 428.88 & 422.5 & 421.87 \\
\hline F1(Rs/hr) & 1379.5 & 1379.4 & 1379.4 \\
\hline F2(Rs/hr) & 2643.1 & 2588.5 & 2584.3 \\
\hline F3(Rs/hr) & 4487.5 & 4388 & 4377.7 \\
\hline Ploss(MW) & 13.361 & 13.159 & 13.139 \\
\hline Total Gen(MW) & 874.88 & 862.76 & 861.55 \\
\hline Total Fuel Cost(Rs/hr) & 8510.1 & 8355.9 & 8341.4 \\
\hline CPU Time(sec) & 6.25 & 6 & 6.0313 \\
\hline Best Trial & 13 & 28 & 50 \\
\hline
\end{tabular}

Table 10. Convergence Results for 10 Generating Units With Valve Point Effect

$\mathrm{PD}=2000 \mathrm{MW}$

No. of Trials $=50$

No. of Population $=5$

Crossoverrate $=0.8$; MutRate $=0.001$

\begin{tabular}{|l|c|}
\hline \multicolumn{1}{|c|}{ Unit power output } & $\begin{array}{c}\text { Optimal Values by } \\
\text { GA }\end{array}$ \\
\hline P1(MW) & 225.6242 \\
\hline P2(MW) & 233.7826 \\
\hline P3(MW) & 330 \\
\hline P4(MW) & 300 \\
\hline P5(MW) & 242 \\
\hline P6(MW) & 160 \\
\hline P7(MW) & 130 \\
\hline P8(MW) & 118 \\
\hline P9(MW) & 80 \\
\hline P10(MW) & 245.9484 \\
\hline Total Power Output(MW) & 2065.3552 \\
\hline Ploss(MW) & 56.872 \\
\hline Total Generation Cost(Rs/h) & 125975.5063 \\
\hline CPU time(sec) & 23.547 \\
\hline Best Trial & 47 \\
\hline
\end{tabular}

\section{CONCLUSION}

In this paper, a comprehensives ED model including ramp rate limits, valve loading effects and transmission losses together is presented. In this method, the genetic algorithm method is found best suited for the fuel cost functions of non-smooth, non-continuous valve point curves. The proposed 
GA can provide a more diverse search of solution space and so better optimum solutions with low computation burden can be found. The research work is under way in order to incorporate more security issues of power system in the ED model with other constraints.

\section{REFERENCES}

[1] A. J. Wood and B. F. Wollenberg. Power generation, Operation and Control. New York: Wiley, 1994.

[2] C. E. Lin and G. L. Viviani. Hierarchical economic dispatch for piecewise quadratic cost functions. IEEE Trans. Power App.Syst., June 1984. Vol. PAS-103, No. 6, pp. 1170-1175.

[3] S. Granville. Optimal reactive dispatch through interior points methods. in Proc, IEEE Summer Meeting, Seattle, WA, 1992, Paper No. 92 SM 416-8 PWRS.

[4] Z. X. Liang and J. D. Glover. A zoom feature for a programming solution to economic dispatch including transmission losses. IEEE Trans.Power Syst., Aug 1992. Vol. 7, No. 3, pp. 544-550.

[5] A. G. Bakirtzis, P. N. Biskas, C. E. Zoumas, and V. Petridis. Optimal power flow by enchanced genetic algorithm. IEEE Trans. Power systems, May 2002, Vol. 17, No. 2, pp. 229-236.

[6] J. Yurevich and K. P. Wong. Evolutionary programming based optimal power flow algorithms. IEEE Trans. Power Syst., November 1999, Vol. 14, No. 4, pp. 1245-250.

[7] T. Kulworawanichpong and S. Sujitjorn. Optimal power flow using Tabu search. IEEE Power Engineering Review, June 2002, Vol. 22, pp. 37-40.

[8] M. A. Abido. Optimal power flow using tabu search algorithm. Electric Power Components and Systems, May 2002, Vol. 30, No. 5, pp. 469-483.

[9] N. Sinha, R. Chakrabarti, and P. K. Chattopadhyay. Evolutionary programming techniques for economic load dispatch. IEEE Trans.Evol.Comput., Feb. 2003, Vol. 7, No. 1, pp.83-94.

[10] H. T. Yang, P. C. Yang and C. L. Huang. Evolutionary programming based Economic Dispatch for units with non-smooth fuel cost functions. IEEE Trans. Power Systems, Feb. 1996, Vol. 11, No. 1, pp. 112-118.

[11] D. E. Goldberg. Genetic Algorithm in Search, Optimization and Machine learning. Reading MA: Addison-Wesley, 1989.

[12] C. T. Su, C. T. Lin. New Approach with a Hopfield modeling framework to economic dispatch of power system. IEEE Transactions Power Systems, 15(2) (2000) 541-545.

[13] C. S. Chang, and W. Fu. Stochastic multiobjective generation dispatch of combined heat and power system. IEEE proceedingsGeneration, Transmission and Distribution, 1998, Vol. 145 (5), pp. 583-591.

[14] A. El-Gallad, M. El-Hawary, A. Sallam, A. Kalas. Swarm intelligence for hybrid cost dispatch problem. Canadian Conf. on Electrical and Computer Engineering, 13-16 May 2001, Vol. 2, pp. 753-757.

[15] W. Lin, F. Cheng, M. Tsay. Nonconvex Economic Dispatch by Integrated Artificial Intelligence. IEEE Trans. on Power Systems, May 2001, Vol. 16, No. 2, pp. 307-311.

[16] J. Park, S. Yang, K. Mun, H. Lee, J. Jung. An application of evolutionary computations to economic load dispatch with piecewise quadratic cost functions. The 1998 IEEE International Conference on Evolutionary Computation, 4-9 May 1998, Vol. 8, No. 3, pp. 289-294.

[17] K. Y. Lee, A. Sode Yone, J. Ho Park. Adaptive Hopfield Neural Networks for Economic Load Dispatch. IEEE Trans. on Power Systems, May 1998, Vol. 13, No. 2, pp. 519-526.

[18] IEEE Committee Report. Present Practices in the Economic Operation of Power Systems. IEEE Transactions on Power Apparatus and Systems, Vol. PAS-90, July/August 1971, pp. 1768-1775.

[19] D. C. Walters, G. B. Sheble. Genetic algorithm solution of economic dispatch with valve point loading. IEEE Trans. Power Systems, August 1993, Vol. 8, No. 3, pp. 1325-1332.

[20] K. Wong, Y. Wong. Genetic and genetic/simulated-annealing approaches to economic dispatch. IEEE Proceedings Gener., Trans. and Distr., Sep 1994, Vol. 141, No. 5, pp. 507-513.

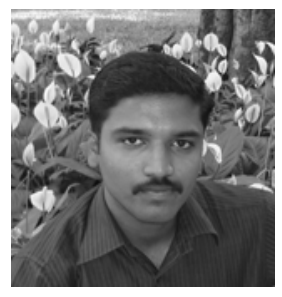

B. Padmanabhan was born on June 26, 1989. He is doing his final year B.E. degree electrical engineering in Ponjesly College of Engineering, Nagercoil, TamilNadu, India.

His area of interest includes and Electrical Machines. 


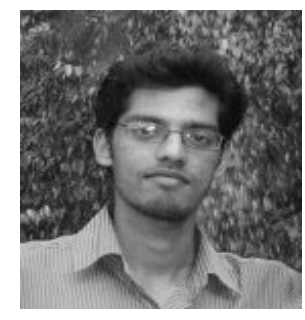

R.S. SivaKumar was born on May 12, 1988. He is doing his final year B.E degree electrical engineering in Ponjesly College of Engineering, Nagercoil, TamilNadu India.

His area of interest includes and Artificial Intelligence. power system optimization,

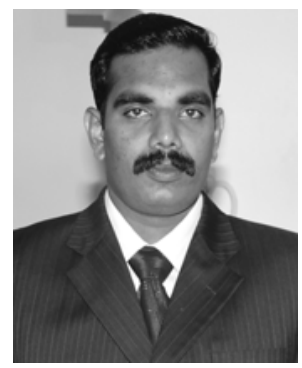

J. Jasper was born on February 28, 1981. He received the B.E. degree electrical engineering in 2003 from C.S.I Institute of Technology, Manonmanium Sundaranar University, TamilNadu, India, and the M.E. degree in electrical engineering in 2005 from Annamalai University,
Chidambaram, India. He is currently working toward the Ph.D. degree with the Faculty of Electrical Engineering, Anna University, Coimbatore, India.

$\mathrm{He}$ is presently a Senior Lecturer in the Department of Electrical Engineering, Ponjesly College of Engineering, Tamilnadu, India.

His major research interest includes power system operation, intelligent control and Electrical Machines. 